\title{
Implementasi Metode SAW Dan TOPSIS Dalam Pemilihan Rumah Hunian Di Wilayah Semarang Barat
}

\author{
Laela Isna Fitrotunnisa ${ }^{1 *}$, Imam Husni Al Amin² \\ 1,2 Teknologi Informasi, Teknik Informatika, Universitas Stikubank, Semarang, Indonesia \\ Jl. Trilomba Juang No 1 Semarang 50241, Kota Semarang, Jawa Tengah \\ Email: ${ }^{1 *}$ laelaisnaf22@gmail.com, ${ }^{2}$ imam@edu.unisbank.ac.id
}

\begin{abstract}
Abstrak - Dalam berumah tangga memiliki tempat tinggal merupakan suatu kebutuhan yang wajib terpenuhi. Namun demikian banyak masyarakat yang kesulitan untuk menentukan rumah hunian yang sesuai dengan kebutuhan dan keinginan saat akan membeli tempat tinggal berupa perumahan. Hal tersebut karena minimnya pengetahuan masyarakat tentang seluk beluk perumahan yang tidak sebanding dengan banyaknya pilihan rumah yang ditawarkan. Sehingga dari permasalahan tersebut dibutuhkan suatu sistem pendukung keputusan untuk membantu masyarakat dalam menentukan rumah hunian yang akan dibeli dan ditinggali. Sistem yang dibuat dapat membantu masyarakat untuk menentukan pilihan rumah hunian berdasarkan kriteria yang sudah disediakan oleh sistem dan ditentukan oleh pengguna. Kriteria yang digunakan meliputi type rumah dengan luas tanah, harga, material bangunan, fasilitas rumah dan akses jalan. Perancangan sistem pendukung keputusan ini mengadopsi dua metode yaitu hybrid SAW (Simple Additive Weighting) dan TOPSIS (Technique for Order Performance of Similarity to Idea Solution). Metode SAW digunakan untuk tahap pembobotan sedangkan metode TOPSIS digunakan untuk proses perangkingan. Dengan penggabungan dua metode ini bertujuan untuk mendapatkan hasil yang tepat. Penelitian ini mendapatkan hasil akhir yaitu 0,83 yang mana merupakan rumah dengan type Town House 14 (A). Hasil ini didapatkan dari seleksi 8 kriteria yang terpilih dan telah dihitung dengan metode hybrid SAW (Simple Additive Weighting) dan TOPSIS (Technique for Order Performance of Similarity to Idea Solution) dan seleksi tersebut menyatakan rumah model Town House 14 (A) merupakan type dengan hasil tertinggi. Masyarakat dapat menggunakan sistem ini dengan mudah karena berbasis website dimana pembuatannya menggunakan bahasa pemrograman PHP dan database MySQL.
\end{abstract}

Kata Kunci: SPK, Hybrid, SAW, TOPSIS, Perumahan

Abstract - In a household, having a place to live is a necessity that must be met. Unfortunately, many people find it difficult to determine a residential house that suits their needs and desires when buying a place to live in the form of housing. This is due to the lack of public knowledge about the ins and outs of housing which is not proportional to the many choices of houses on offer. So that from these problems a decision support system is needed to assist the community in determining which residential house to buy and live in. The system created can help the community to determine the choice of residential houses based on the criteria that have been provided by the system and determined by the user. The criteria used include the type of house with land area, price, building materials, house facilities and road access. The design of this decision support system adopts two methods, namely hybrid SAW (Simple Additive Weighting) and TOPSIS (Technique for Order Performance of Similarity to Idea Solution). The SAW method is used for the weighting stage while the TOPSIS method is used for the ranking process. By combining these two methods the aim is to get the right results. This study obtained the final result of 0.83 , which is a house with the type of Town House 14 (A). These results are obtained from the selection of 8 selected criteria and have been calculated using the hybrid SAW (Simple Additive Weighting) and TOPSIS (Technique for Order Performance of Similarity to Idea Solution) methods and the selection states that the Town House 14 (A) model house is a type with the results highest. People can use this system easily because it is based on a website where it is made using the PHP programming language and MySQL database.

Keywords: SPK, Hybrid, SAW, TOPSIS, Housing

\section{PENDAhuluan}

Banyaknya kebutuhan akan tempat tinggal semakin meningkat yang tidak diimbangi dengan padatnya penduduk membuat tempat hunian seperti perumahan menjadi salah satu alternatif untuk masyarakat agar mendapatkan tempat tinggal yang layak. Perumahan menjadi salah satu contoh pilihan yang tepat untuk masyarakat yang ingin membeli rumah hunian. Rumah hunian merupakan suatu hal yang wajib dimiliki terkhusus bagi masyarakat yang sudah berumah tangga karena termasuk kebutuhan primer [1]. Namun pada kenyataannya memilih rumah hunian tidaklah mudah seperti yang dibayangkan. Pemilihan rumah hunian merupakan suatu hal yang patut di pertimbangkan bagi keluarga yang akan membeli rumah hunian. Rumah ini akan menjadi tempat tinggal yang cukup lama atau bisa juga untuk tempat tinggal selamanya sehingga harus diperhatikan betul mulai dari type rumah dengan luas tanah, harga rumah, material bangunan, fasilitas rumah, dan akses jalan dapat digunakan sebagai bahan pertimbangan dalam memilih rumah hunian. Setiap orang memiliki kriteria tersendiri untuk menentukan rumah hunian pilihan yang di inginkan. Terdapat permasalahan dalam menentukan pilihan rumah hunian terbaik sesuai dengan kebutuhan dan keinginan. Hal tersebut muncul karena minimnya 
pengetahuan yang dimiliki oleh masyarakat umum terhadap seluk beluk perumahan yang tidak sebanding dengan banyaknya pilihan perumahan yang tersebar di wilayah Semarang Barat. Perumahan adalah kumpulan rumah yang sering menjadi pilihan untuk dijadikan tempat tinggal, terlebih untuk keluarga baru agar bisa hidup mandiri [2]. Didalam lingkungan perumahan biasanya sudah terdapat beberapa bangunan atau tempat seperti masjid atau gereja sebagai tempat ibadah, taman atau zona bermain untuk anak, minimarket dan ada juga beberapa perumahan yang sudah menyediakan tempat belajar atau sekolahan. Oleh karena itu sangat diperlukan pertimbangan untuk memilih rumah hunian. Wilayah Semarang barat banyak tersedia perumahan dengan banyak pilihan tipe dan unit rumah. Salah satu perumahan yang ada di Semarang barat yaitu perumahan Green Oase Homy Residence yang terletak di Jl. Walisongo KM. 9, Tugu Semarang. Perumahan ini memiliki lima jenis tipe rumah dengan unit yang cukup banyak. Seringkali calon pembeli / konsumen kesulitan untuk menentukan rumah yang akan dibeli dengan berbagai alasan. Padahal memilih rumah merupakan suatu hal yang paling penting untuk di pikirkan secara matang. Dengan adanya suatu sistem yang dapat mempermudah masyarakat maka akan sangat membantu dalam merekomendasikan rumah hunian berdasarkan kriteria yang ada. Dengan permasalahan ini maka diperlukan sistem pendukung keputusan yang dapat membantu masyarakat dalam menentukan pilihan rumah hunian di wilayah Semarang Barat yaitu dengan menggunakan metode hybrid SAW (Simple Additive Weighting) dan TOPSIS (Technique for Order Performance of Similarity to Idea Solution) sebagai pembobotan terhadap kriteria dan perangkingan terhadap alternatif yang ada sehingga mendapatkan hasil yang lebih maksimal. Sebagai bahan pertimbangan untuk user diberikan beberapa kriteria yang digunakan didalam sistem agar dapat dipilih dan diisi sehingga akan mendapat hasil yang tepat dan sesuai. Harapannya sistem yang dibuat dapat bermanfaat untuk membantu masyarakat di wilayah Semarang Barat dan sekitarnya yang belum berpengalaman dalam memilih tempat tinggal yang berkualitas dan sesuai dengan kebutuhan dan keinginan. Hal ini bertujuan agar masyarakat tidak salah pilih dalam menentukan tempat tinggal sehingga tidak akan menyesal dengan rumah yang dibeli.

Metode hybrid merupakan metode penggabungan dimana dengan metode ini dapat digunakan untuk menggabungkan dua metode atau lebih agar bisa digunakan untuk menentukan hasil perhitungan dari perpaduan metode. Metode SAW (Simple Additive Weighting) yaitu metode yang sudah sering digunakan oleh peneliti untuk melakukan penelitian karena metode ini diaggap sebagai metode yang paling mudah untuk diterapkan. Namun untuk hasil yang lebih maksimal biasanya metode SAW (Simple Additive Weighting) dipakai dengan cara digabugkan dengan metode lain. Pada penelitian ini metode TOPSIS (Technique for Order Performance of Similarty to Idea Solution) digunakan untuk menyempurnakan penelitian dengan digabungkan metode SAW (Simple Additive Weighting). Untuk melakukan perhitungan metode SAW (Simple Additivve Weighting) digunakan terlebih dahulu untuk menghitung nilai pembobotan pada setiap kriteria di tiap alternatif nya kemudian akan dilanjutkan dengan menggunakan metode TOPSIS (Technique for Order Performance of Similarity to Idea Solution) sebagai tahapan proses akhir untuk melakukan proses perangkingan terhadap alternatif. Penelitian sejenis sudah pernah dilakukan sebelumnya dengan menggunakan metode SAW dan TOPSIS untuk melakukan penelitian terhadap pemilihan tempat Barbershop di Kota Malang. Penelitian ini menggunakan tujuh kriteria sebagai pembanding yaitu: jumlah barber, harga, jarak, fasilitas, jam operasional, sistem booking, dan sistem voucher [3]. Dilihat dari penelitian terdahulu yang dilakukan oleh peneliti dapat disimpulkan bahwa sangat penting melakukan penelitian dengan sistem pendukung keputusan untuk menentukan suatu keputusan yang tepat dalam berbagai masalah yang ada. Pemilihan dapat dilakukan dengan berbagai macam metode, beberapa metode yang sering digunakan dalam sistem pendukung keputusan seperti fuzzy, AHP, MADM dan yang lainnya. Namun untuk penelitian kali ini peneliti akan menggunakan metode hybrid SAW (Simple Additive Weighting) dan TOPSIS (Technique for Order Performance of Similarity to Ideal Solution) untuk menentukan pilihan dalam mencari rumah hunian di wilayah Semarang Barat. Metode yang digunakan merupakan penggabungan dari metode SAW (Simple Additive Weighting) untuk proses pembobotan dan metode TOPSIS (Technique for Order Performance of Similarity to Idea Solution) digunakan untuk proses perangkingan.

\section{METODE PENELITIAN}

\subsection{Sistem Pendukung Keputusan}

Pengertian sistem pendukung keputusan adalah suatu sistem yang berfungsi untuk menyelesasikan suatu persoalan atau sistem pemecah untuk masalah terstruktur[4]. Sistem pendukung keputusan juga disebut sebagai suatu sistem yang berbasis komputer dengan tiga komponen yang saling berinteraksi yaitu bahasa, pengetahuan dan pemrosesan masalah[5]. Sistem pendukung keputusan selain digunakan untuk menyelesaikan masalah juga sebagai alat bantu untuk mendukung proses pengambilan keputusan[6].

\subsection{Metode Pengembangan Sistem}


Dalam penelitian ini penulis menggunakan metode prototype untuk pengembangan Sistem. Metode prototype merupakan metode yang sering digunakan dalam penelitian. Model prototype merupakan suatu proses yang dapat dilakukan developer dalam membuat suatu model software apabila konsumen atau client tidak bisa memberikan informasi yang dibutuhkan secara maksimal. Berikut tahapan pengembangan nya.

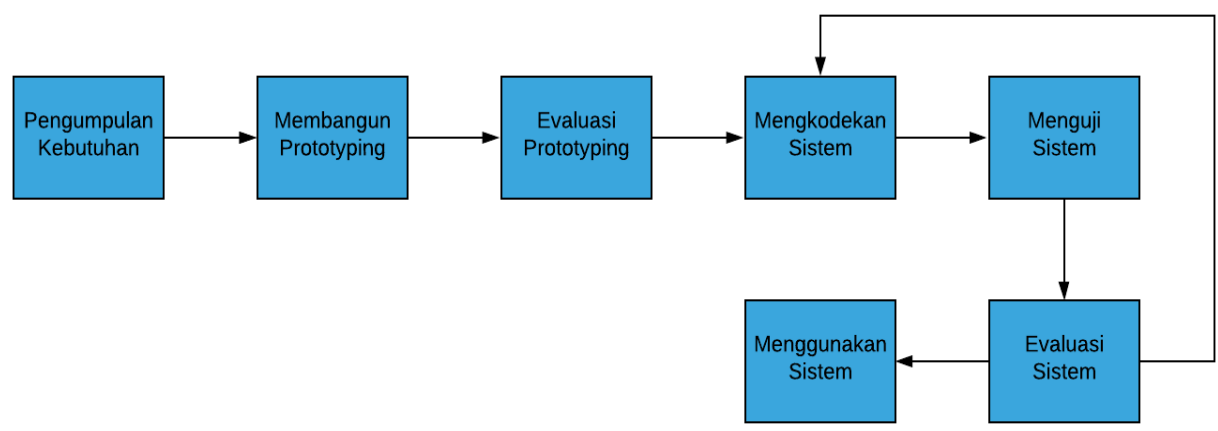

Gambar 1. Tahapan Prototype

\subsection{Hybrid SAW dan TOPSIS}

Metode SAW merupakan metode yang tergolong mudah dipahami. Metode ini dikenal dengan metode penjumlahan berbobot[7]. Konsep dasar SAW yaitu mencari penjumlahan terbobot pada setiap alternatif[8]. Metode SAW memerlukan proses normalisasi matriks keputusan X untuk ke suatu skala yang dapat dibandingkan dengan semua alternatif[9]. Dalam penelitian ini SAW digabungkan dengan metode TOPSIS yang mana berfungsi sebagai perangkingan tiap alternatif yang diurutkan dari nilai tertinggi ke nilai terendah[10]. TOPSIS memiliki konsep bahwa alternatif terbaik tidak hanya yang memiliki jarak terpendek dengan solusi idea positif tetapi juga jarak terpanjang dari solusi idea negatif[11][12]. Metode ini banyak digunakan sebagai pengambilan keputusan secara efisien. Hal tersebut dikarenakan konsepnya mudah dipahami dan mempunyai kemampuan kerja relatif dari alternatif keputusan[13].

Dalam pengimplementasian metode SAW dan TOPSIS untuk pemilihan rumah hunian di wilayah Semarang Barat dibutuhkan tahapan - tahapan guna untuk mendapatkan hasil yang sesuai dengan harapan. Berikut adalah tahapan atau proses untuk sistem rekomendasi dalam memilih rumah hunian.

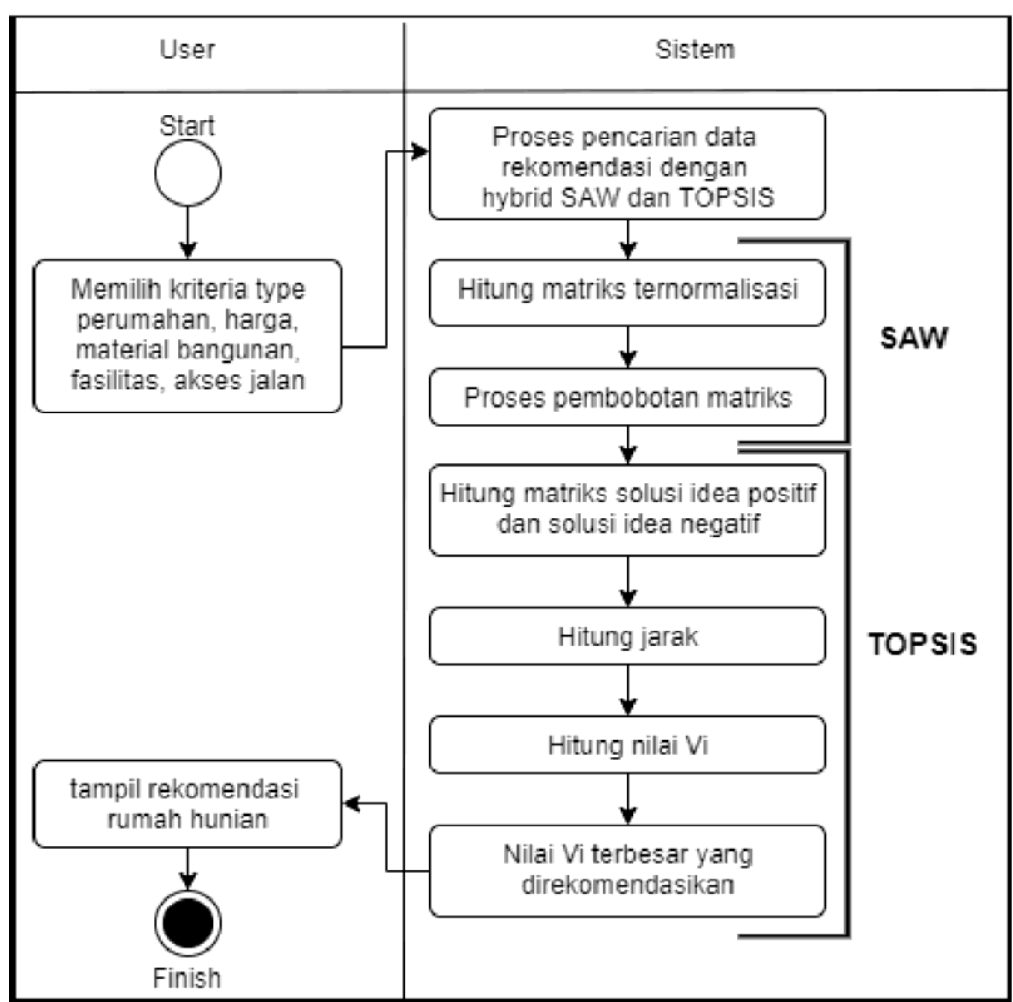

Gambar 2. Tahapan Sistem 
Proses perhitungan matriks ternormalisasi dan proses pembobotan terhadap kriteria dilakukan dengan menggunakan metode SAW. Selanjutnya untuk proses perhitungan matriks dengan solusi idea positif dan matriks solusi idea negatif, perhitungan jarak antara solusi idea positif dan solusi idea negatif, serta menghitung nilai Vi untuk menentukan nilai preferensi pada tiap alternatif menggunakan metode TOPSIS sehingga akan mendapatkan hasil perangkingan yang kemudian akan ditampilkan oleh sistem untuk user [14].

\subsection{Perhitungan Menggunakan Metode Hybrid SAW dan Topsis}

Untuk melakukan perhitungan menggunakan metode hybrid SAW dan TOPSIS dapat dilakukan dengan langkah - langkah sebagai berikut [15]:

a. Menentukan nilai bobot setiap kriteria

(Bobot kriteria didapatkan dari hasil pengisian kuesioner online yang disebarkan ke masyarakat)

b. Menentukan nilai kecocokan

c. Melakukan normalisali kecocokan

$R_{i j}=\frac{x_{i j}}{\max x_{i j}}$ jika j atribut keuntungan (benefit)

Digunakan untuk menghitung nilai kriteria type, material bangunan, fasilitas rumah dan akses jalan.

$R_{i j}=\frac{\min x_{i j}}{x_{i j}}$ jika j atribut keuntungan (cost)

Digunakan untuk menghitung nilai kriteria harga.

d. Membuat matriks keputusan yang ternormalisasi terbobot matriks y

$y_{i j}=\sum_{j=1}^{n} w_{j} r_{i j}$

e. Membuat matriks solusi idea positif $\left(\mathrm{A}^{+}\right)$dan matriks solusi idea negative $\left(\mathrm{A}^{-}\right)$berdasarkan rating bobot ternormalisasi $\mathrm{y}_{\mathrm{ij}}$

$Y=\left[\begin{array}{lllll}y_{11} & y_{12} & y_{13} & y_{14} & y_{15} \\ y_{21} & y_{22} & y_{23} & y_{14} & y_{25}\end{array}\right]$

f. Menentukan matriks solusi idea positif $\left(\mathrm{A}^{+}\right)$

$A^{+}=y_{1}^{+}, y_{2}^{+}, \ldots \ldots y_{n}^{+}$

g. Menentukan matriks solusi idea negatif $\left(\mathrm{A}^{-}\right)$

$A^{-}=y_{1}^{-}, y_{2}^{-}, \ldots \ldots y_{n}^{-}$

h. Menentukan jarak terbobot setiap alternatif terhadap solusi idea positif $\left(S_{i}^{+}\right)$

$\left.D_{i}^{+}=\sqrt{\sum_{j=1}^{n}\left(y_{i}^{+}+\right.} y_{i}\right)^{2}$

i. Menentukan jarak terbobot setiap alternatif terhadap solusi idea negatif $\left(S_{i}^{-}\right)$

$\left.D_{i}^{+}=\sqrt{\sum_{j=1}^{n}\left(y_{i j}-\right.} y_{i}\right)^{2}$

j. $\quad$ Nilai preferensi untuk setiap alternatif $\left(\mathrm{V}_{\mathrm{i}}\right)$ dengan rumus $V_{i}=\frac{D_{i}^{-}}{D_{i}^{-}+D_{i}^{+}}$

\section{HASIL DAN PEMBAHASAN}

Tahapan ini akan dijelaskan proses perhitungan dengan menggunakan metode hybrid SAW (Simple Additive Weighting) dan metode TOPSIS (Technique for Order Performance of Similarity to Idea Soltion) yang digunakan untuk menghitung pemilihan unit rumah di perumahan Green Oase. Hasil pengujian dilakukan dengan perhitungan terhadap studi kasus yang ada, yaitu dengan melakukan perhitungan menggunakan metode hybrid SAW (Simple Additive Weighting) dan TOPSIS (Technique for Order Performance of Similarity to Idea Soltion) dalam pencarian rumah hunian di wilayah Semarang Barat dengan memilih kriteria material bangunan 1 dari 3 pilihan kriteria material bangunan, memilih fasilitas 4 dari 8 kriteria fasilitas rumah yang disediakan dan akses jalan 5 meter.

Untuk detail dari kriteria material bangunan 1 meliputi pondasi menerus batu kali dengan struktur beton bertulang, dinding bata merah diplaster aci, atap beton archon / setara, sanitair American standar / setara, plafon rangka baja ringan gypsum, lantai granit tile, rangka baja ringan, listrik meter PLN 2200VA, meter air, tandan bawah tanah dan pompa air. Dan detail untuk fasilitas 4 yaitu 3 kamar tidur, 2 kamar mandi, dapur, ruang tamu, dan carport. Dari kriteria tersebut maka tersedia beberapa rumah yang akan menjadi alternatif untuk dipilih oleh pengguna, berikut adalah tabel data perumahan yang akan menjadi alternatif berdasarkan kriteria yang telah dipilih. 
Tabel 1. Data Perumahan Berdasarkan Kriteria

\begin{tabular}{ccccccc}
\hline No. & Model & $\begin{array}{c}\text { Type } \\
\text { (LT) }\end{array}$ & Harga & Material & $\begin{array}{c}\text { Fasilitas } \\
\text { Akses } \\
\text { jalan }\end{array}$ \\
\hline 1. & Townhouse 2 (A) & $168 \mathrm{M}^{2}$ & 1.354 .800 .000 & 1 & 4 & 5 \\
2. & Townhouse 3 (A) & $161 \mathrm{M}^{2}$ & 1.319 .400 .000 & 1 & 4 & 5 \\
3. & Townhouse 6 (A) & $132 \mathrm{M}^{2}$ & 1.172 .700 .000 & 1 & 4 & 5 \\
4. & Townhouse 10 (A) & $191 \mathrm{M}^{2}$ & 1.471 .200 .000 & 1 & 4 & 5 \\
5. & Townhouse 11 (A) & $175 \mathrm{M}^{2}$ & 1.390 .200 .000 & 1 & 4 & 5 \\
6. & Townhouse 12(A) & $182 \mathrm{M}^{2}$ & 1.425 .700 .000 & 1 & 4 & 5 \\
7. & Townhouse 12B (A) & $188 \mathrm{M}^{2}$ & 1.456 .000 .000 & 1 & 4 & 5 \\
8. & Townhouse 14(A) & $242 \mathrm{M}^{2}$ & 1.729 .300 .000 & 1 & 4 & 5 \\
\hline
\end{tabular}

Setelah data perumahan sudah didapatkan maka dalam melakukan perhitungan dengan metode hybrid SAW dan TOPSIS untuk menentukan pilihan rumah hunian di wilayah Semarang Barat perlu digunakan kriteria. Adapun kriteria yang digunakan dalam melakukan perhitungan untuk menentukan pilihan rumah hunian di wilayah Semarang Barat menggunakan metode hybrid SAW (Simple Additive Weighting) dan TOPSIS (Technique for Order Performance of Similarity to Idea Solution).

Tabel 2. Kriteria

\begin{tabular}{ccc}
\hline Notasi & Kriteria & Atribut \\
\hline C1 & Type / Luas Tanah & Benefit \\
C2 & Harga & Cost \\
C3 & Material Bangunan & Benefit \\
C4 & Fasilitas Rumah & Benefit \\
C5 & Akses Jalan & Benefit \\
\hline
\end{tabular}

Kemudian untuk pembobotan (w) diperoleh dari hasil kuesioner yang dilakukan terhadap masyarakat sebanyak 100 responden. Kuesioner yang didapatkan merupakan kuesioner secara acak dari masyarakat dengan latar belakang pekerjaan dan usia yang berbeda - beda.

Perolehan hasil kuesioner dapat dilihat pada gambar diagram lingkaran yang didapatkan dari 100 suara responden.

100 responses

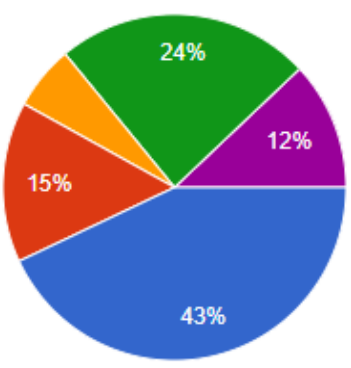

Type Perumahan Dan Luas Tanah

Fasilitas

Material Bangunan

Akses Jalan

Harga

Gambar 3. Diagram lingkaran kuesioner

Dari diagram di atas dapat dihitung pembobotan kriteria yang didapatkan yaitu sebagai berikut pada tabel dibawah. Data bobot (W) didapat dengan cara hasil persentase tiap kriteria dibagi 100. Nilai 100 didapatkan dari jumlah keseluruhan responden sehingga mendapatkan hasil yang tepat.

Tabel 3. Pembobotan Kriteria

\begin{tabular}{ccc}
\hline Kriteria & Bobot & Bobot $(\mathrm{W})$ \\
\hline Type / Luas Tanah & 43 & 0,43 \\
$(\mathrm{C} 1)$ & 12 & 0,12 \\
$\begin{array}{c}\text { Harga } \\
\text { (C2) }\end{array}$ & & 0,06 \\
$\begin{array}{c}\text { Material Bangunan } \\
\text { (C3) }\end{array}$ & 6 & 0,15 \\
Fasilitas & 15 &
\end{tabular}




\begin{tabular}{ccc}
\hline (C4) & 24 & 0,24 \\
$\begin{array}{c}\text { Akses Jalan } \\
(\mathrm{C} 5)\end{array}$ & 100 & 1 \\
\hline
\end{tabular}

\subsection{Perhitungan Metode Hybrid SAW dan TOPSIS}

Untuk melakukan perhitungan pemilihan rumah hunian di wilayah Semarang Barat dengan kriteria type rumah dengan luas tanah, harga, material bangunan, fasilitas rumah dan akses jalan digunakan langkah - langkah algoritma hybrid SAW (Simple Additive Weighting) dan TOPSIS (Technique for Order Performance of Similarity to Idea Solution) secara berurutan sebagai berikut.

1. Membuat matriks keputusan $X$ yang didapatkan dari data perumahan berdasarkan kriteria yang sudah ditentukan sebelumnya. Data matriks didapatkan dengan cara memasukkan nilai tiap kriteria yang dimiliki oleh setiap alternatif.

$$
X=\left[\begin{array}{lllll}
r 11 & r 12 & r 13 & r 14 & r 15 \\
r 21 & r 22 & r 23 & r 24 & r 25 \\
r 31 & r 32 & r 33 & r 34 & r 35 \\
r 41 & r 42 & r 43 & r 44 & r 45 \\
r 51 & r 52 & r 53 & r 54 & r 55 \\
r 61 & r 62 & r 63 & r 64 & r 65 \\
r 71 & r 72 & r 73 & r 74 & r 75 \\
r 81 & r 82 & r 83 & r 84 & r 85
\end{array}\right] \text { Hasil, } X=\left[\begin{array}{lllll}
168 & 1.354 .800 .000 & 1 & 4 & 5 \\
161 & 1.319 .400 .000 & 1 & 4 & 5 \\
132 & 1.172 .700 .000 & 1 & 4 & 5 \\
191 & 1.471 .200 .000 & 1 & 4 & 5 \\
175 & 1.390 .200 .000 & 1 & 4 & 5 \\
182 & 1.425 .700 .000 & 1 & 4 & 5 \\
188 & 1.456 .000 .000 & 1 & 4 & 5 \\
242 & 1.729 .300 .000 & 1 & 4 & 5
\end{array}\right]
$$

2. Menormalisasikan matriks dengan rumus persamaan (1) digunakan untuk menormalisasikan kriteria type perumahan dengan luas tanah, material bangunan, fasilitas rumah dan akses jalan karena kriteria tersebut termasuk nilai keuntungan (benefit) dan rumus persamaan (2) digunakan untuk kriteria harga karena merupakan kriteria biaya (cost).

Keterangan:

$\mathrm{i} \quad=$ Nilai alternatif

$\mathrm{j} \quad=$ Nilai kriteria

$\mathrm{r}_{\mathrm{ij}} \quad$ = Nilai rating kerja ternormalisasi

$\mathrm{x}_{\mathrm{ij}}=$ Nilai atribut yang dimiliki dari tiap kriteria

a. Normalisasi matriks untuk kriteria type rumah dengan luas tanah $(\mathrm{C} 1)$

Hasil normalisasi matriks untuk kriteria type rumah denga luas tanah didapatkan dari perhitungan dengan cara pembagian $\mathrm{x}_{\mathrm{ij}}$ dibagi max $\mathrm{x}_{\mathrm{ij}}$. Dimana nilai maksimal dari kriteria type rumah dengan luas tanah yaitu 242. Sehingga nilai rating $\mathrm{x}_{\mathrm{ij}}$ tiap alternatif dibagi 242 yang mana merupakan nilai rating tertinggi dari kriteria type rumah dengan luas tanah.

Tabel 4. Normalisasi Matriks Type Rumah

\begin{tabular}{lcc}
\hline & Nilai Rating & Hasil \\
\hline $\mathrm{R}_{11}$ & 168 & 0,694214876 \\
$\mathrm{R}_{21}$ & 161 & 0,665289256 \\
$\mathrm{R}_{31}$ & 132 & 0,545454545 \\
$\mathrm{R}_{41}$ & 191 & 0,789256198 \\
$\mathrm{R}_{51}$ & 175 & 0,723140496 \\
$\mathrm{R}_{61}$ & 182 & 0,752066116 \\
$\mathrm{R}_{71}$ & 188 & 0,776859504 \\
$\mathrm{R}_{81}$ & 242 & 1 \\
\hline
\end{tabular}

b. Normalisasi matriks untuk kriteria harga (C2)

Hasil normalisasi matriks untuk kriteria harga didapatkan dari perhitungan dengan cara pembagian min $\mathrm{x}_{\mathrm{ij}}$ dibagi $\mathrm{x}_{\mathrm{ij}}$. Dimana nilai minimal dari kriteria harga yaitu 1.172.700.000,-. Sehingga nilai rating minimal dari kriteria harga yaitu 1.172 .700 ,- dibagi dengan nilai rating $\mathrm{x}_{\mathrm{ij}}$ dari tiap alternatif. 
Tabel 5. Normalisasi Matriks Harga

\begin{tabular}{lcc}
\hline & Nilai Rating & Hasil \\
\hline $\mathrm{R}_{12}$ & 1.354 .800 .000 & 0,865589017 \\
$\mathrm{R}_{22}$ & 1.319 .400 .000 & 0,888813097 \\
$\mathrm{R}_{32}$ & 1.172 .700 .000 & 1 \\
$\mathrm{R}_{42}$ & 1.471 .200 .000 & 0,797104405 \\
$\mathrm{R}_{52}$ & 1.390 .200 .000 & 0,843547691 \\
$\mathrm{R}_{62}$ & 1.425 .700 .000 & 0,822543312 \\
$\mathrm{R}_{72}$ & 1.456 .000 .000 & 0,805425824 \\
$\mathrm{R}_{82}$ & 1.729 .300 .000 & 0,678135662 \\
\hline
\end{tabular}

c. Normalisasi matriks untuk kriteria material bangunan (C3)

Hasil normalisasi matriks untuk kriteria material bangunan didapatkan dari perhitungan dengan cara pembagian $\mathrm{x}_{\mathrm{ij}}$ dibagi max $\mathrm{x}_{\mathrm{ij}}$. Dimana nilai maksimal dari material bangunan yaitu 1 , karena semua alternatif yang ada mempunyai nilai rating yang sama maka hasil perhitungan menunjukkan nilai sama dimana $\mathrm{x}_{\mathrm{ij}}$ tiap kriteria yang bernilai 1 dan dibagi dengan nilai rating tertingggi yaitu 1 maka akan menghasilkan hasil akhir untuk kriteria material banguan sama yaitu 1,00 .

Tabel 6. Normalisasi Matriks Material Bangunan

\begin{tabular}{lcc}
\hline & Nilai Rating & Hasil \\
\hline $\mathrm{R}_{13}$ & 1 & 1,00 \\
$\mathrm{R}_{23}$ & 1 & 1,00 \\
$\mathrm{R}_{33}$ & 1 & 1,00 \\
$\mathrm{R}_{43}$ & 1 & 1,00 \\
$\mathrm{R}_{53}$ & 1 & 1,00 \\
$\mathrm{R}_{63}$ & 1 & 1,00 \\
$\mathrm{R}_{73}$ & 1 & 1,00 \\
$\mathrm{R}_{83}$ & 1 & 1,00 \\
\hline
\end{tabular}

d. Normalisasi matriks untuk kriteria fasilitas rumah (C4)

Hasil normalisasi matriks untuk kriteria fasilitas rumah didapatkan dari perhitungan dengan cara pembagian $\mathrm{x}_{\mathrm{ij}}$ dibagi max $\mathrm{x}_{\mathrm{ij}}$. Dimana nilai maksimal dari fasilitas rumah yaitu 4 , karena semua alternatif yang ada mempunyai nilai rating yang sama maka hasil perhitungan menunjukkan nilai sama dimana $\mathrm{x}_{\mathrm{ij}}$ tiap kriteria yang bernilai 4 dan dibagi dengan nilai rating tertinggi yaitu 4 maka akan menghasilkan nilai akhir untuk kriteria fasilitas rumah sama yaitu 1,00.

Tabel 7. Normalisasi Matriks Fasilitas Rumah

\begin{tabular}{lcc}
\hline & Nilai Rating & Hasil \\
\hline $\mathrm{R}_{14}$ & 4 & 1,00 \\
$\mathrm{R}_{24}$ & 4 & 1,00 \\
$\mathrm{R}_{34}$ & 4 & 1,00 \\
$\mathrm{R}_{44}$ & 4 & 1,00 \\
$\mathrm{R}_{54}$ & 4 & 1,00 \\
$\mathrm{R}_{64}$ & 4 & 1,00 \\
$\mathrm{R}_{74}$ & 4 & 1,00 \\
$\mathrm{R}_{84}$ & 4 & 1,00 \\
\hline
\end{tabular}

e. Normalisasi matriks untuk kriteria akses jalan (C5)

Hasil normalisasi matriks untuk kriteria material bangunan didapatkan dari perhitungan dengan cara pembagian $\mathrm{x}_{\mathrm{ij}}$ dibagi max $\mathrm{x}_{\mathrm{ij}}$. Dimana nilai maksimal dari material bangunan yaitu 5 , karena semua alternatif yang ada mempunyai nilai rating yang sama maka hasil perhitungan menunjukkan nilai sama dimana $\mathrm{x}_{\mathrm{ij}}$ tiap kriteria yang bernilai 5 dan dibagi dengan nilai rating tertinggi yaitu 5 maka akan menghasilkan nilai akhir yang sama untuk tiap kriteria yaitu 1,00. 
Tabel 8. Normalisasi Matriks Akses Jalan

\begin{tabular}{lcc}
\hline & Nilai Rating & Hasil \\
\hline $\mathrm{R}_{15}$ & 5 & 1,00 \\
$\mathrm{R}_{25}$ & 5 & 1,00 \\
$\mathrm{R}_{35}$ & 5 & 1,00 \\
$\mathrm{R}_{45}$ & 5 & 1,00 \\
$\mathrm{R}_{55}$ & 5 & 1,00 \\
$\mathrm{R}_{65}$ & 5 & 1,00 \\
$\mathrm{R}_{75}$ & 5 & 1,00 \\
$\mathrm{R}_{85}$ & 5 & 1,00 \\
\hline
\end{tabular}

3. Matriks keputusan yang ternormalisasi terbobot matriks Y dengan rumus persamaan (3) Untuk melakukan perhitungan dengan persamaan (3) perlu diperhatikan bahwa $\mathrm{w}_{\mathrm{j}}$ merupakan bobot kriteria yang sebelumnya sudah dilakukan pencarian dengan cara dibagi 100 responden. Lalu untuk $\mathrm{r}_{\mathrm{ij}}$ merupakan nilai rating tiap alternatif yang sudah ternormalisasi.

a. Matriks keputusan ternormalisasi terbobot untuk alternatif 1 Townhouse 2 (A)

Tabel 9. Matriks Keputusan Ternormalisasi Terbobot A1

\begin{tabular}{cccccc}
\hline A1 & $\mathrm{Y}_{11}$ & $\mathrm{Y}_{12}$ & $\mathrm{Y}_{13}$ & $\mathrm{Y}_{14}$ & $\mathrm{Y}_{15}$ \\
\hline & 0,298512397 & 0,103870682 & 0,06 & 0,15 & 0,24 \\
\hline
\end{tabular}

b. Matriks keputusan ternormalisasi terbobot untuk alternatif 2 Townhouse 3 (A)

Tabel 10. Matriks Keputusan Ternormalisasi Terbobot A2

\begin{tabular}{cccccc}
\hline $\mathrm{A} 2$ & $\mathrm{Y}_{21}$ & $\mathrm{Y}_{22}$ & $\mathrm{Y}_{23}$ & $\mathrm{Y}_{24}$ & $\mathrm{Y}_{25}$ \\
\hline & 0,28607438 & 0,106657572 & 0,06 & 0,15 & 0,24 \\
\hline
\end{tabular}

c. Matriks keputusan ternormalisasi terbobot untuk alternatif 3 Townhouse 6 (A)

Tabel 11. Matriks Keputusan Ternormalisasi Terbobot A3

\begin{tabular}{cccccc}
\hline $\mathrm{A} 3$ & $\mathrm{Y}_{31}$ & $\mathrm{Y}_{32}$ & $\mathrm{Y}_{33}$ & $\mathrm{Y}_{34}$ & $\mathrm{Y}_{35}$ \\
\hline & 0,234545454 & 0,12 & 0,06 & 0,15 & 0,24 \\
\hline
\end{tabular}

d. Matriks keputusan ternormalisasi terbobot untuk alternatif 4 Townhouse 10 (A)

Tabel 12. Matriks Keputusan Ternormalisasi Terbobot A4

\begin{tabular}{cccccc}
\hline $\mathrm{A} 4$ & $\mathrm{Y}_{41}$ & $\mathrm{Y}_{42}$ & $\mathrm{Y}_{43}$ & $\mathrm{Y}_{44}$ & $\mathrm{Y}_{45}$ \\
\hline & 0,339380165 & 0,095652529 & 0,06 & 0,15 & 0,24 \\
\hline
\end{tabular}

e. Matriks keputusan ternormalisasi terbobot untuk alternatif 5 Townhouse 11 (A)

Tabel 13. Matriks Keputusan Ternormalisasi Terbobot A5

\begin{tabular}{cccccc}
\hline A5 & $\mathrm{Y}_{51}$ & $\mathrm{Y}_{52}$ & $\mathrm{Y}_{53}$ & $\mathrm{Y}_{54}$ & $\mathrm{Y}_{55}$ \\
\hline & 0,310950413 & 0,101225723 & 0,06 & 0,15 & 0,24 \\
\hline
\end{tabular}

f. Matriks keputusan ternormalisasi terbobot untuk alternatif 6 Townhouse 12 (A)

Tabel 14. Matriks Keputusan Ternormalisasi Terbobot A6

\begin{tabular}{cccccc}
\hline $\mathrm{A} 6$ & $\mathrm{Y}_{61}$ & $\mathrm{Y}_{62}$ & $\mathrm{Y}_{63}$ & $\mathrm{Y}_{64}$ & $\mathrm{Y}_{65}$ \\
\hline & 0,32338843 & 0,098705197 & 0,06 & 0,15 & 0,24 \\
\hline
\end{tabular}

g. Matriks keputusan ternormalisasi terbobot untuk alternatif 7 Townhouse 12B (A)

Tabel 15. Matriks Keputusan Ternormalisasi Terbobot A7

\begin{tabular}{cccccc}
\hline A7 & $\mathrm{Y}_{71}$ & $\mathrm{Y}_{72}$ & $\mathrm{Y}_{73}$ & $\mathrm{Y}_{74}$ & $\mathrm{Y}_{75}$ \\
\hline & 0,334049587 & 0,096651099 & 0,06 & 0,15 & 0,24 \\
\hline
\end{tabular}


h. Matriks keputusan ternormalisasi terbobot untuk alternatif 8 Townhouse 14 (A)

Tabel 16. Matriks Keputusan Ternormalisasi Terbobot A8

\begin{tabular}{cccccc}
\hline $\mathrm{A} 8$ & $\mathrm{Y}_{81}$ & $\mathrm{Y}_{82}$ & $\mathrm{Y}_{83}$ & $\mathrm{Y}_{84}$ & $\mathrm{Y}_{85}$ \\
\hline & 0,43 & 0,081376279 & 0,06 & 0,15 & 0,24 \\
\hline
\end{tabular}

4. Membuat matriks solusi idea positif $\left(\mathrm{A}^{+}\right)$dan matriks solusi idea negatif $\left(\mathrm{A}^{-}\right)$berdasarkan rating bobot ternormalisasi $\mathrm{y}_{\mathrm{ij}}$. Nilai matriks didapatkan dari rumus persamaan (4) atau hasil matriks keputusan ternormalisasi terbobot pada tiap alternatif nya.

$Y=\left[\begin{array}{ccccc}0,298512397 & 0,103870682 & 0,06 & 0,15 & 0,24 \\ 0,28607438 & 0,106657572 & 0,06 & 0,15 & 0,24 \\ 0,234545454 & 0,12 & 0,06 & 0,15 & 0,24 \\ 0,339380165 & 0,095652529 & 0,06 & 0,15 & 0,24 \\ 0,310950413 & 0,101225723 & 0,06 & 0,15 & 0,24 \\ 0,32338843 & 0,098705197 & 0,06 & 0,15 & 0,24 \\ 0,334049587 & 0,096651099 & 0,06 & 0,15 & 0,24 \\ 0,43 & 0,081376279 & 0,06 & 0,15 & 0,24\end{array}\right]$

5. Menentukan matriks solusi idea positif $\left(\mathrm{A}^{+}\right)$

Dari matriks $\mathrm{Y}$ dapat dicari yang merupakan matriks solusi idea positif $\left(\mathrm{A}^{+}\right)$dengan cara mencari nilai tertinggi dari setiap baris y yang ada atau dengan rumus persamaan (5) sehingga akan mendapatkan hasil pada tabel.

Tabel 17. Solusi Idea Positif

\begin{tabular}{lc}
\hline $\mathrm{A}^{+}$ & Hasil \\
\hline$y_{1}^{+}$ & 0,43 \\
$y_{2}^{+}$ & 0,12 \\
$y_{3}^{+}$ & 0,06 \\
$y_{4}^{+}$ & 0,15 \\
$y_{5}^{+}$ & 0,24 \\
\hline
\end{tabular}

6. Menentukan matriks solusi idea negatif $\left(\mathrm{A}^{-}\right)$

Dari matriks $\mathrm{Y}$ dapat dicari yang merupakan matriks solusi idea negatif $\left(\mathrm{A}^{-}\right)$dengan cara mencari nilai terendah dari setiap baris y yang ada atau dengan rumus persamaan (6) sehingga akan mendapat hasil pada tabel.

Tabel 18. Solusi Idea Negatif

\begin{tabular}{cc}
\hline $\mathrm{A}^{-}$ & Hasil \\
\hline$y_{1}^{-}$ & 0,234545454 \\
$y_{2}^{-}$ & 0,081376279 \\
$y_{3}^{-}$ & 0,06 \\
$y_{4}^{-}$ & 0,15 \\
$y_{5}^{-}$ & 0,24 \\
\hline
\end{tabular}

7. Menentukan jarak terbobot setiap alternatif terhadap solusi idea positif $\left(S_{i}^{+}\right)$dan jarak terbobot setiap alternatif terhadap solusi idea negatif $\left(S_{i}^{-}\right)$

Jarak terbobot tiap alternatif terhadap solusi idea positif dapat dicari dengan rumus persamaan (7) dan jarak terbobot tiap alternatif terhadap solusi idea negatif dapat dicari dengan rumus persamaan (8) sehingga akan mendapatkan hasil untuk tiap alternatif nya dimana nilai tersebut akan digunakan untuk menghitung hasil akhir dari perangkingan tiap alternatif nya.

Tabel 19. Jarak Terhadap Solusi Idea Positif Dan Negatif

\begin{tabular}{clcc}
\hline & Alternatif & D+ & D- \\
\hline V1 & Townhouse 2 (A) & 0,147616921 & 0,086461346 \\
V2 & Townhouse 3 (A) & 0,157268048 & 0,076810219 \\
V3 & Townhouse 6 (A) & 0,195454546 & 0,038623721 \\
\hline
\end{tabular}




\begin{tabular}{lccc}
\hline V4 & Townhouse 10 (A) & 0,114967306 & 0,119110961 \\
V5 & Townhouse 11 (A) & 0,137823864 & 0,096254403 \\
V6 & Townhouse 12 (A) & 0,127906373 & 0,106171894 \\
V7 & Townhouse 12B (A) & 0,119299314 & 0,114778953 \\
V8 & Townhouse 14 (A) & 0,038623721 & 0,195454546 \\
\hline
\end{tabular}

8. Menentukan nilai preferensi untuk setiap alternatif $\left(\mathrm{V}_{\mathrm{i}}\right)$ dengan rumus persamaan (9) agar mendapatkan hasil perangkingan untuk pemilihan rumah dimana $D_{i}^{-}$merupakan jarak terbobot tiap alternatif terhadap solusi idea negatif, sedangkan $D_{i}^{+}$merupakan jarak terbobot tiap alternatif terhadap solusi idea positif.

$$
\begin{aligned}
& V_{1}=\frac{0,08}{0,08+0,14}=\frac{0,08}{0,22}=0,36 \\
& V_{2}=\frac{0,07}{0,07+0,15}=\frac{0,07}{0,22}=0,32 \\
& V_{3}=\frac{0,04}{0,04+0,19}=\frac{0,04}{0,23}=0,17 \\
& V_{4}=\frac{0,12}{0,12+0,1}=\frac{0,12}{0,22}=0,55 \\
& V_{5}=\frac{0,09}{0,09+0,13}=\frac{0,09}{0,22}=0,41 \\
& V_{6}=\frac{0,1}{0,1+0,12}=\frac{0,1}{0,22}=0,45 \\
& V_{7}=\frac{0,11}{0,11+0,11}=\frac{0,11}{0,22}=0,50 \\
& V_{8}=\frac{0,19}{0,19+0,04}=\frac{0,19}{0,23}=\mathbf{0 , 8 3}
\end{aligned}
$$

Menurut hasil perhitungan $\mathbf{V}_{\mathbf{8}}$ merupakan alternatif yang mendapatkan nilai terbesar. Maka rumah model Town House 14 (A) menjadi alternatif yang terpilih karena memperoleh bobot nilai paling tinggi yaitu 0,83. Dengan demikian dibuat tabel hasil yang sudah diurutkan dengan nilai tertinggi ke nilai terendah.

Tabel 20. Hasil Perhitungan

\begin{tabular}{cccccccc}
\hline No. & Model & $\begin{array}{c}\text { Type } \\
(\mathrm{LT})\end{array}$ & Harga & Material & Fasilitas & $\begin{array}{c}\text { Akses } \\
\text { jalan }\end{array}$ & Nilai \\
\hline 1. & Townhouse 14 (A) & $242 \mathrm{M}^{2}$ & 1.729 .300 .000 & 1 & 4 & 5 & 0,83 \\
2. & Townhouse 10 (A) & $191 \mathrm{M}^{2}$ & 1.471 .200 .000 & 1 & 4 & 5 & 0,55 \\
3. & Townhouse 12B (A) & $188 \mathrm{M}^{2}$ & 1.456 .000 .000 & 1 & 4 & 5 & 0,50 \\
4. & Townhouse 12 (A) & $182 \mathrm{M}^{2}$ & 1.425 .700 .000 & 1 & 4 & 5 & 0,45 \\
5. & Townhouse 11 (A) & $175 \mathrm{M}^{2}$ & 1.390 .200 .000 & 1 & 4 & 5 & 0,40 \\
6. & Townhouse 2 (A) & $168 \mathrm{M}^{2}$ & 1.354 .800 .000 & 1 & 4 & 5 & 0,36 \\
7. & Townhouse 3 (A) & $161 \mathrm{M}^{2}$ & 1.319 .400 .000 & 1 & 4 & 5 & 0,32 \\
8. & Townhouse 6 (A) & $132 \mathrm{M}^{2}$ & 1.172 .700 .000 & 1 & 4 & 5 & 0,17 \\
\hline
\end{tabular}

\subsection{Implementasi Sistem}

Setelah melakukan perhitungan dengan metode hybrid SAW dan TOPSIS maka selanjutnya yaitu melakukan pengimplementasian terhadap sistem pendukung keputusan sebagai berikut 


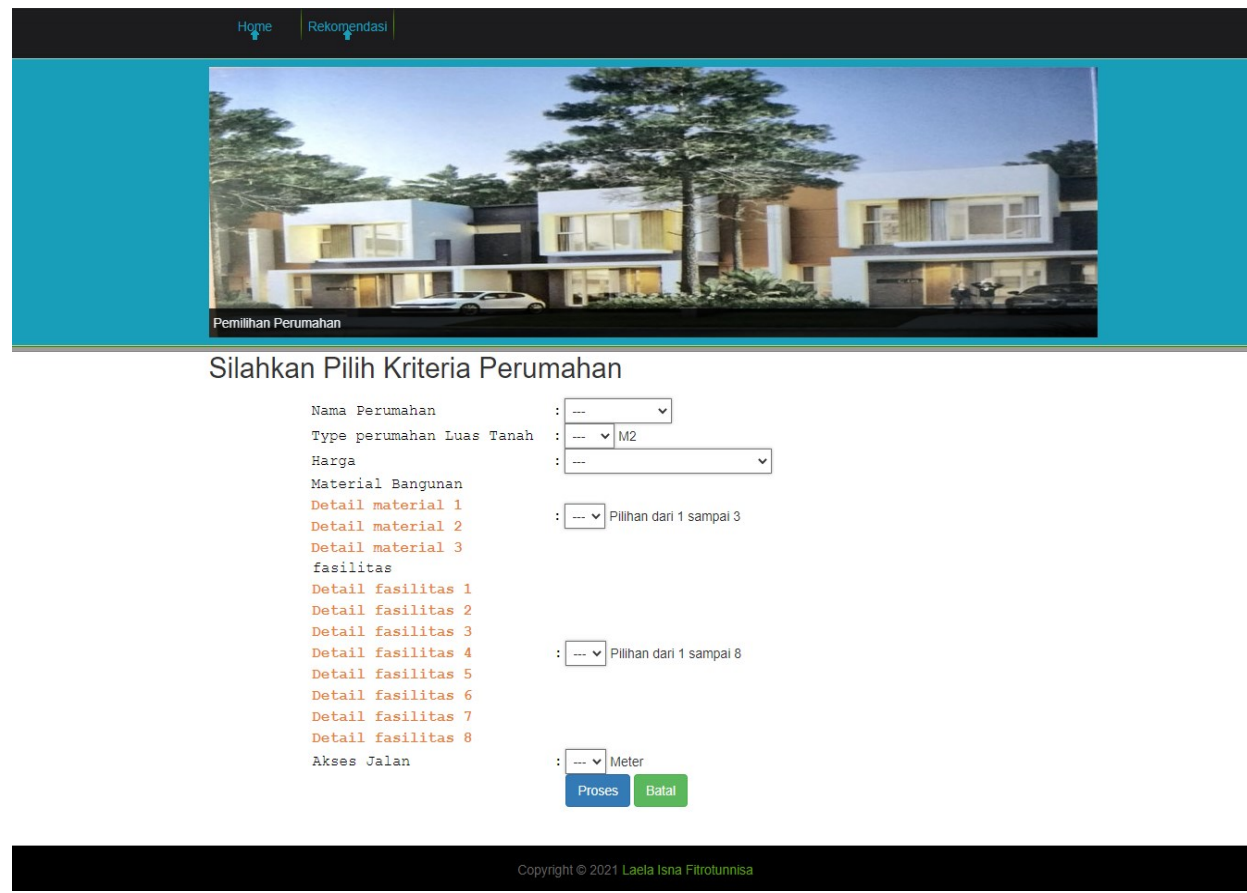

Gambar 4. Halaman rekomendasi

Pada halaman ini user diminta untuk mengisi kriteria rumah hunian yang di inginkan. Untuk kriteria material bangunan dan fasilitas user dapat melihat detail dibawah nya terlebih dahulu untuk mengetahui lebih jelas pilihan yang disediakan kemudian user dapat memilih angka sesuai dengan detail yang di pilih.

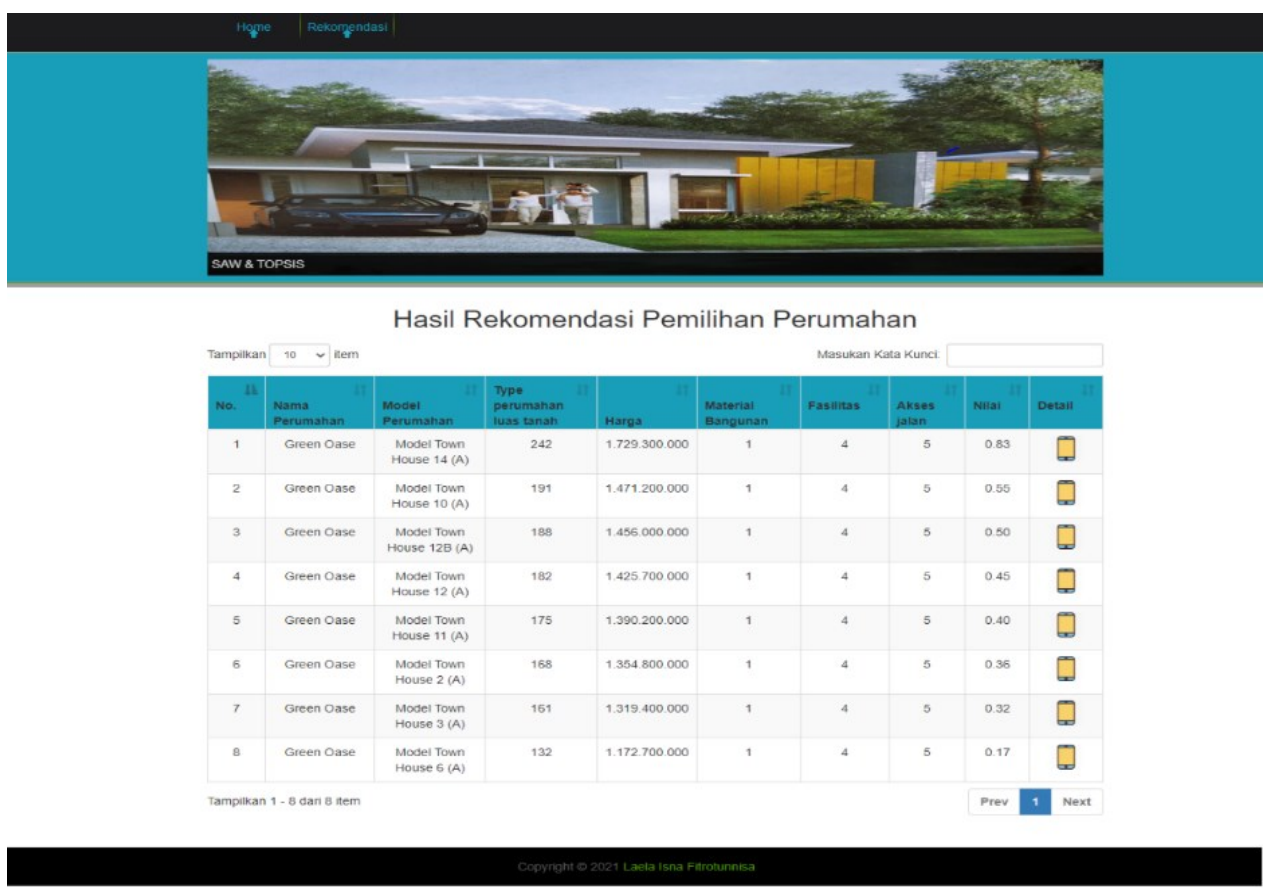

Gambar 5. Hasil Rekomendasi Sistem

Pada halaman ini ditampilkan hasil rekomendasi berdasarkan kriteria yang telah ditentukan sebelumnya oleh user. Hasil tersebut didapatkan dari kriteria yang dimasukkan user kemudian diproses dengan perhitungan hybrid SAW (Simple Additive Weighting) dan TOPSIS (Technique for Order Performance of Similarity to Idea Solution) setelah proses selesai maka hasil ditampilkan seperti gambar diatas yang sudah diurutkan dengan rangking atau bobot nilai tertinggi ke terendah.

Dari pengujian perhitungan menggunakan metode Hybrid SAW (Simple Additive Weighting) dan TOPSIS (Technique for Order Performance of Similarity To Idea Solution) dengan sistem pendukung keputusan yang 
sudah dibuat menunjukkan kecocokan hasi akhir nilai bobot 100\%. Dengan demikian penelitian ini dapat dikatakan berhasil.

\section{KESIMPULAN}

Sistem pendukung keputusan dibuat dengan menggunakan metode hybrid SAW dan TOPSIS untuk menghasilkan output berupa rekomendasi rumah yang sudah diurutkan dari nilai tertinggi ke nilai terendah. Dibuatnya sistem ini bertujuan agar sistem dapat dimanfaatkan oleh masyarakat yang ingin membeli rumah hunian sehingga dapat menghemat waktu dalam memilih dan mendapatkan pilihan rumah yang tepat sesuai dengan kebutuhan dan keinginan. Dipilihnya metode SAW karena berperan penting dalam proses pembobotan nilai dan metode TOPSIS berperan untuk menghasilkan perangkingan terhadap alternatif yang ada sehingga dapat menentukan hasil terbaik dari alternatif yang ada. Peneliti menggunakan lima kriteria untuk memudahkan pengguna dalam menggunakan sistem. Kriteria yang disediakan oleh sistem pendukung keputusan ini meliputi type perumahan dengan luas tanah, harga unit rumah, material bangunan yang digunakan, fasilitas rumah dan akses jalan perumahan.

Dalam melakukan perhitungan dengan metode hybrid SAW dan TOPSIS untuk menentukan pilihan rumah hunian di wilayah Semarang Barat digunakan kriteria dan pembobotan (w) yang didapatkan dari hasil kuesioner terhadap masyarakat sebanyak 100 responden. Hasil pembobotan kriteria dengan bobot (w) masing masing kriteria yaitu type perumahan dengan luas tanah mendapat nilai pembobotan 0,43 , kriteria harga mendapatkan nilai bobot 0,12 , material bangunan mendapatkan nilai bobot (w) 0,06 , untuk fasilitas rumah mendapatkan nilai bobot 0,15 dan yang terakhir yaitu kriteria akses jalan dengan hasil pembobotan 0,24. Pembobotan ini digunakan untuk menghitung nilai tiap alternatif yang ada. Dalam penelitian sistem pendukung keputusan dengan metode hybrid SAW dan TOPSIS dalam pemilihan rumah hunian di wilayah Semarang Barat ini mendapatkan hasil akhir nilai tertinggi yaitu 0,83 yang mana nilai tersebut didapatkan oleh alternatif 8 atau V8 yang berarti rumah model TOWN HOUSE 14 (A) merupakan alternatif yang direkomendasikan oleh sistem dengan pemilihan kriteria material bangunan nomor satu, fasilitas empat dan akses jalan lima meter.

Dari hasil tersebut rekomendasi terbaik yaitu rumah model TOWN HOUSE 14 (A) dengan detail type perumahan dengan luas tanah $242 \mathrm{~m}^{2}$, harga perumahan 1.729.300.000, material bangunan nomer satu, fasilitas rumah yang didapatkan berupa 3 kamar tidur, 2 kamar mandi, 1 dapur untuk memasak, 1 ruangan yang bisa digunakan untuk ruang tamu atau ruang keluarga, dan carport yang bisa digunakan untuk parker satu mobil atau sepeda motor dengan akses jalan depan rumah 5 meter. Adapun saran yang diberikan oleh penulis untuk pembaca yaitu agar pengembangan sistem ini nantinya dapat diterapkan untuk objek yang berbeda dengan kriteria yang berbeda. Jumlah kriteria mungkin dapat ditambahkan lebih banyak agar hasil yang didapatkan lebih akurat dan tepat. Sistem ini juga dapat dikembangkan dengan menambah atau menggunakan metode yang berbeda dari yang sebelumnya.

\section{REFERENCES}

[1] E. A. Dipawinata, "Perancangan Aplikasi Berbasis Web dengan Sistem Pendukung Keputusan Pemilihan Tempat Tinggal Menggunakan Metode Profile Matching (PM),” 2021.

[2] F. Andriansyah, R. B. Aplikasi, E. V. Haryanto, and A. Saleh, "Design And Build Smart Security Application For Housing Using Android Based QR Code,” Aug. 2020. Accessed: Jun. 02, 2021. [Online]. Available: http://ejournal.potensi-utama.ac.id/ojs/index.php/FTIK/article/view/871.

[3] D. E. Prastyawati, "Implementasi metode Simple Additive Weighting (SAW) dan technique for order performance of similarity to ideal solution (TOPSIS) dalam pemilihan barbershop di Kota Malang,” Dec. 2019.

[4] G. Setiawan, I.H. Al Amin, “AHP Method for Selecting Wood As Furniture Raw Material,” vol. 13, no. 1, pp. 3746, 2020.

[5] H. N. Sari and A. Fatmawati, "Sistem Pendukung Keputusan Rekomendasi Penentu Beras Miskin Menggunakan Metode SAW Dan TOPSIS (Studi Kasus: Desa Semagar Girimarto Wonogiri)," J. Mitra Manaj., vol. 3, no. 1, pp. 96-108, 2019, doi: 10.52160/ejmm.v3i1.185.

[6] H. Sibyan, "Implementasi Metode SMART pada Sistem Pendukung Keputusan Penerima Beasiswa Sekolah,” J. Penelit. dan Pengabdi. Kpd. Masy. UNSIQ, vol. 7, no. 1, pp. 78-83, 2020, doi: 10.32699/ppkm.v7i1.1055.

[7] P. Non et al., “Sistem Pendukung Keputusan Penerima Bantuan,” vol. 17, no. 2, pp. 200-208, 2020.

[8] R. Hardianto, "Spk Pemilihan Presiden Mahasiswa Unilak Menggunakan Metode Simple Additive Weighting (Saw),” Zo. J. Sist. Inf., vol. 1, no. 2, pp. 97-103, 2020, doi: 10.31849/zn.v1i2.3123. 
Menggunakan Fuzzy Multiple Atribute Decision Making Dengan Metode Simple Additive Weighting Studi Kasus Pada Sma Islam Sultan Agung 1 Semarang," J. Transform., vol. 11, no. 2, p. 69, 2014, doi: 10.26623/transformatika.v11i2.98.

[10] Sunarti, "Perbandingan Metode TOPSIS dan SAW Untuk Pemilihan Rumah Tinggal," J. Inf. Syst., vol. 3, no. 1, pp. 69-79, 2018, [Online]. Available: https://publikasi.dinus.ac.id/index.php/joins/article/view/1883/1289.

[11] M. Rasyid Ridho, H. Hairani, K. Abd Latif, and R. Hammad, "Kombinasi Metode AHP dan TOPSIS untuk Rekomendasi Penerima Beasiswa SMK Berbasis Sistem Pendukung Keputusan,” J. Tekno Kompak, vol. 15, no. 1, pp. 26-39, 2021, [Online]. Available: https://ejurnal.teknokrat.ac.id/index.php/teknokompak/article/view/905.

[12] Fahmi, Mohamad Helmi Ilman; I.H. Al Amin, "Best Products With Topsis Method and Sales Forecasting With Weighted Moving Average,” vol. 4, no. 2, pp. 116-123, 2020.

[13] M. D. Sena and Suparmadi, "Sistem Pendukung Keputusan Untuk Menentukan Peserta Terbaik Dalam Perlombaan Penulisan Kaligrafi Dengan Metode Topsis,” J. Sci. Soc. Res., vol. 3, no. 1, pp. 26-32, 2020.

[14] W. Hadikurniawati, I. A. Nugraha, and T. D. Cahyono, "Implementasi Metode Hybrid Saw-Topsis Dalam Multi Attribute Decision Making Pemilihan Laptop," JURTEKSI (Jurnal Teknol. dan Sist. Informasi), vol. 7, no. 2, pp. 127-132, 2021, doi: 10.33330/jurteksi.v7i2.907.

[15] D. Amaliyah, "Sistem Pendukung Keputusan Pemilihan Handphone Menggunakan Metode Hybrid SAW dan TOPSIS," Jan. 2020. 